\section{J-based Configuration Analysis: An Enabling NMR- Spectroscopic Tool in the Synthesis and Study of Chlorinated Natural Products}

\section{Christian Nilewski and Erick M. Carreira*}

${ }^{*}$ Correspondence: Prof. Dr. E. M. Carreira, ETH Zürich, HCl H335, CH-8093 Zürich, Tel.: +41 4463228 30, Fax: +4144632 1328 E-mail: erickm.carreira@org.chem.ethz.ch

Keywords: Chlorosulfolipids · Heteronuclear coupling constants $\cdot J$-based configuration analysis $\cdot$ Natural products Organohalogens

To date, more than 4700 naturally occurring organohalogens are known. Chlorosulfolipids, which are produced by seaand freshwater microalgae alike, constitute a particularly intriguing subclass of naturally occurring organohalogens. Many interdisciplinary questions, reaching from chemistry to biology, pharmacology and toxicology - not the least of which is their association with seafood poisoning - have rendered these molecules interesting objects for study. In this context, reliable tools to secure configurational assignment are critical. As part of our synthetic program directed toward the total synthesis and study of chlorosulfolipids, we investigated the applicability of an NMR-based approach, $J$-based configuration analysis (JBCA), to chlorinated systems.

Unlike in cyclic entities, the analysis of vicinal $\left({ }^{3} \mathrm{~J}\right)$ coupling constants and NOE data alone is usually insufficient to elucidate the conformation and configuration of acyclic systems. Key to overcome these shortcomings is the extraction and analysis of a whole set of homo- $\left({ }^{3} J_{\mathrm{H} H}\right)$ and heteronuclear $\left({ }^{2} J_{\mathrm{CH}},{ }^{3} J_{\mathrm{CH}}\right)$ coupling constants along two stereogenic centers bearing electronegative substituents, in addition to NOE and ROE data. For chlorinated entities, reference values for the relevant coupling constants were lacking. In order to fill the existing gap, we developed synthetic routes to a collection of trichlorinated hexane-1,3- and-1,2-diols, starting from commercially available ethyl sorbate, which served as model compounds for NMR-spectroscopic studies. All of these proved to be crystalline, which allowed us to directly correlate all NMR data with the configuration known from X-ray analysis. Extraction of the vicinal $\mathrm{H}, \mathrm{H}$-coupling constants ( $\left.{ }^{1} \mathrm{H}-\mathrm{NMR}\right)$ as well as the $\mathrm{C}, \mathrm{H}$-coupling constants over two and three bonds (HSQC-HECADE, PS-HMBC) allowed us to define ranges for the coupling constants as a function of the configuration and conformation. The lessons learnt in these studies are invaluable for the configurational assignment and conformational analysis of polychlorinated natural products such as chlorosulfolipids and crucial for any research directed towards the elucidation of the biological role of these molecules in the producing organisms. In summary, we have validated JBCA for chlorinated systems by detailed NMR- and X-ray analysis of trichlorohexanediol model systems.

Received: August 10, 2011

\section{References}

C. Nilewski, R. W. Geisser, E. M. Carreira, Nature 2009, 457, 573 .

C. Nilewski, R. W. Geisser, M.-O. Ebert, E. M. Carreira, J. Am. Chem. Soc. 2009 , $131,15866$.

C. Nilewski, N. R. Deprez, T. C. Fessard, D. B. Li, R. W. Geisser, E. M. Carreira, Angew. Chem. 2011, early view (DOI: 10.1002/ange.201102521); Angew. Chem. Int. Ed. 2011, early view (DOI: 10.1002/anie.201102521).

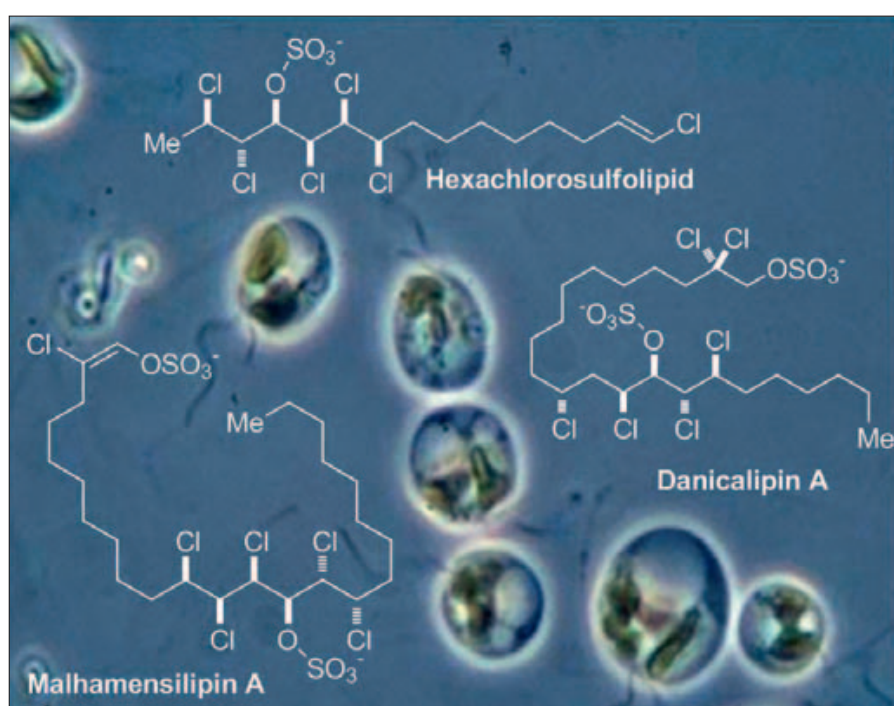

Selected members of the chlorosulfolipid natural product family originating from microalga, such as the chrysophyte Poterioochromonas malhamensis (background taken from http://starcentral.mbl.edu/mv/ portal.php?pagetitle =assetfactsheet\&imageid=22998). a)
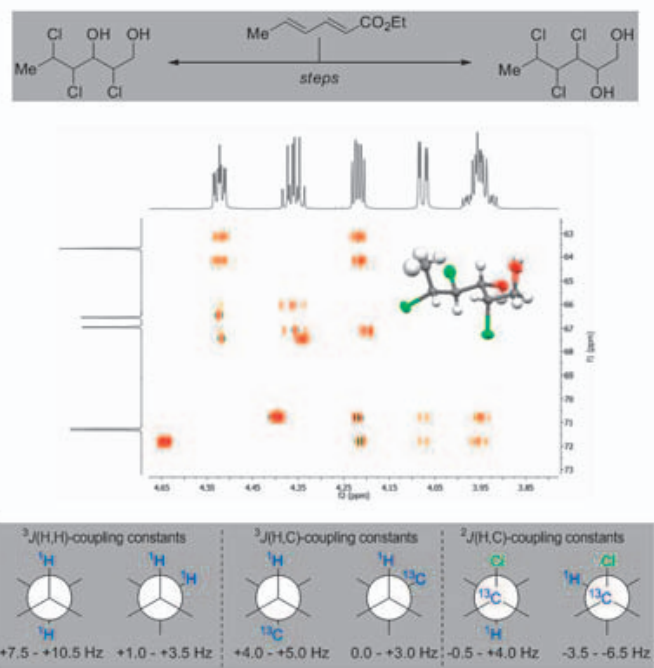

The synthesis of trichlorinated hexanediol model systems (a) and subsequent $\mathrm{X}$-ray-structural and NMR-spectroscopic analysis $(b)$ allowed for the definition of ranges for homo- and heteronuclear coupling constants for chlorinated systems as a function of configuration and conformation (c). 